\title{
Equatorial electrojet studies from rocket and ground measurements
}

\author{
H. Chandra ${ }^{1}$, H. S. S. Sinha ${ }^{1}$, and R. G. Rastogi ${ }^{1,2}$ \\ ${ }^{1}$ Physical Research Laboratory, Ahmedabad, India 380009 \\ ${ }^{2}$ Gujarat University, Ahmedabad, India 380009
}

(Received July 5, 1999; Revised November 4, 1999; Accepted November 15, 1999)

\begin{abstract}
Combining the data of in-situ measurements of ionospheric current, $J_{\mathrm{m}}$ by rocket-borne instruments and the ground based geomagnetic $H$ field close to the magnetic equator a linear relation has been found between the peak current density $J_{\mathrm{m}}$ and the daily range of $H,\left(R_{\mathrm{H}}\right)$. This relationship has been used to convert long series of $R_{\mathrm{H}}$ data into $J_{\mathrm{m}}$. Combining $J_{\mathrm{m}}$ and the $E$-region peak electron density $N_{\mathrm{m}}$, the electron velocity in the ionosphere, $V_{\mathrm{E}}$ has been calculated. It is shown that after all corrections are made of the solar zenith angle variations, the ionospheric current as well as electron drift in American and Indian sectors show strong equinoctial maxima, the mean values of both the parameters are larger at American than in Indian sector. The solar cycle variation of the electrojet current is primarily due to the variations of $N_{\mathrm{m}} E$, and not due to the variations of electric field. The diurnal variation of the electric field with peak at $09-10 \mathrm{LT}$ interacting with noon peak of $N_{\mathrm{m}} E$ making $\Delta H$ to peak at an hour earlier than noon. It is stressed to realise the importance of electric field in diurnal, seasonal and longitudinal variations of the equatorial electrojet current.
\end{abstract}

\section{Introduction}

The first regular geomagnetic observatory close the magnetic equator was established at Trivandrum, India in 1841. The observations were restricted to the declination component and significant solar daily, seasonal and solar cycle variations were shown (Broun, 1874). Later, a standard geomagnetic observatory was established in India at Kodaikanal in 1902 by the Survey of India, as a base station for the magnetic survey, which is located within three degrees from the magnetic equator. An ionospheric radio sounding station was also established at Kodaikanal in 1952 and both the ionospheric and the magnetic observations are continued even today. It is clear now that the latitudinal variation of $\Delta H$ has significant longitudinal effects.

However it was the establishment of a geomagnetic observatory at Huancayo, Peru in 1922 that brought into attention the abnormally large solar daily variations of the horizontal component, $H$, at an equatorial station. Combining the data from Huancayo with the data from the low latitude stations Kodaikanal, Madras in India and Antipolo and Batavia, Egedal (1947) showed that an enhancement in the solar daily variation of $H, S_{\mathrm{q}} H$, occurs within $5^{\circ}$ latitude centred on the dip equator. He suggested this enhancement was caused by a band of electric current of about $300 \mathrm{~km}$ in width flowing over the dip equator which was later named "Equatorial electrojet" by Chapman (1951).

During the International Geophysical Year, IGY, several geomagnetic observatories were established within the equatorial electrojet (EEJ) belt. In Peru new observatories

Copy right $\odot$ The Society of Geomagnetism and Earth, Planetary and Space Sciences (SGEPSS); The Seismological Society of Japan; The Volcanological Society of Japan; The Geodetic Society of Japan; The Japanese Society for Planetary Sciences. at Yauca, Chimbote, Chiclayo and Talara covered the whole width of the EEJ. In India new observatories were established at Trivandrum and Annamalainagar. EEJ observatories were organised at Koror, Jarvis and Ibadan. Table 1 gives the coordinates and the magnetic field parameters of some of these observatories.

Chapman and Rajarao (1965) showed that the seasonal variations of the range in $H$ as well as in $Z$ at the equatorial electrojet stations have strong semi-annual wave with maxima during equinoctial months. Analysing the lunar tides in the critical frequency of the $F_{2}$ layer, $f_{0} F_{2}$, at equatorial stations in Peru and in India during the IGY period, Rastogi (1962a) predicted that the equatorial electrojet current strength must be stronger in Peru than in India. Later using the geomagnetic data from the equatorial observatories during IGY, Rastogi (1962b) confirmed that the electrojet current is indeed stronger in Peru than in India. The strength of the electrojet current was shown to vary roughly inversally to the background mean value of the geomagnetic field $H$ at the station. It was suggested that the electrical conductivity over the magnetic equator is inversally proportional to the strength of the $H$ field.

If equatorial electrojet is a part of the global $S_{\mathrm{q}}$ current system, modified close to the magnetic equator, the day to day variations in the strength of the equatorial electrojet should correlate with the corresponding variations in the strength of the $S_{\mathrm{q}}$ currents at low latitudes outside the electrojet belt. However the daily ranges of $H$ at different latitudes were found not to correlate well (Osborne, 1966; Schlapp, 1968; Kane, 1971). James et al. (1996) has shown that the correlation of $\Delta H$ at an equatorial station, Trivandrum, with $\Delta H$ at other stations in India decreases with increasing latitude. It becomes almost zero around $25^{\circ} \mathrm{N}$ geographic latitude, negative around $35^{\circ} \mathrm{N}$ latitude 
Table 1. List of equatorial geomagnetic observatories with co-ordinates and magnetic field parameters.

\begin{tabular}{llrcrrr}
\hline Observatory & Code & $\begin{array}{c}\text { Geog. Lat. } \\
\text { Deg. }\end{array}$ & $\begin{array}{c}\text { Geog. Long. } \\
\text { Deg. }\end{array}$ & $\begin{array}{c}H \\
\text { nT }\end{array}$ & $\begin{array}{c}Z \\
\text { nT }\end{array}$ & $\begin{array}{c}I \\
\text { Deg. }\end{array}$ \\
\hline Huancayo & HUA & $12.1^{\circ} \mathrm{S}$ & $75.3^{\circ} \mathrm{W}$ & 27225 & 985 & $1.9^{\circ} \mathrm{N}$ \\
Yauca & YUC & $15.9^{\circ} \mathrm{S}$ & $74.7^{\circ} \mathrm{W}$ & 27900 & -2149 & $4.4^{\circ} \mathrm{S}$ \\
Chimbote & $\mathrm{CMB}$ & $9.1^{\circ} \mathrm{S}$ & $78.6^{\circ} \mathrm{W}$ & 29700 & 3257 & $6.3^{\circ} \mathrm{N}$ \\
Chiclayo & $\mathrm{CHL}$ & $6.8^{\circ} \mathrm{S}$ & $79.8^{\circ} \mathrm{W}$ & 30300 & 5381 & $9.7^{\circ} \mathrm{N}$ \\
Talara & TAL & $4.6^{\circ} \mathrm{S}$ & $81.3^{\circ} \mathrm{W}$ & 30700 & 7385 & $12.5^{\circ} \mathrm{N}$ \\
Trivandrum & TRD & $8.5^{\circ} \mathrm{N}$ & $77.0^{\circ} \mathrm{E}$ & 39896 & -232 & $0.6^{\circ} \mathrm{S}$ \\
Kodaikanal & $\mathrm{KOD}$ & $10.2^{\circ} \mathrm{N}$ & $77.5^{\circ} \mathrm{E}$ & 39265 & 2444 & $3.5^{\circ} \mathrm{N}$ \\
Annamalainagar & $\mathrm{ANN}$ & $11.4^{\circ} \mathrm{N}$ & $79.7^{\circ} \mathrm{E}$ & 40309 & 4213 & $5.4^{\circ} \mathrm{N}$ \\
Addis-Ababa & $\mathrm{AAE}$ & $9.0^{\circ} \mathrm{N}$ & $38.8^{\circ} \mathrm{E}$ & 36075 & 407 & $0.5^{\circ} \mathrm{N}$ \\
Koror & $\mathrm{KOR}$ & $7.3^{\circ} \mathrm{N}$ & $134.5^{\circ} \mathrm{E}$ & 37959 & -404 & $0.1^{\circ} \mathrm{S}$ \\
Jarvis & $\mathrm{JAR}$ & $0.4^{\circ} \mathrm{N}$ & $160.1^{\circ} \mathrm{W}$ & 34462 & 778 & $2.2^{\circ} \mathrm{N}$ \\
Ibadan & IBD & $7.5^{\circ} \mathrm{N}$ & $3.9^{\circ} \mathrm{E}$ & 32198 & -4819 & $8.5^{\circ} \mathrm{S}$ \\
Guam & $\mathrm{GUM}$ & $13.6^{\circ} \mathrm{N}$ & $144.9^{\circ} \mathrm{E}$ & 35805 & 7239 & $12.9^{\circ} \mathrm{N}$ \\
Fanning Island & FAN & $3.9^{\circ} \mathrm{N}$ & $159.4^{\circ} \mathrm{W}$ & 32928 & 6148 & $10.6^{\circ} \mathrm{N}$ \\
\hline
\end{tabular}

and again becomes zero at a station north of the $S_{\mathrm{q}}$ focus. This was suggested due to the superimposition of an additional current system over the normal $S_{\mathrm{q}}$ current system. Later James et al. (1997) isolated a low latitude current system centred at $5^{\circ}$ dip latitude superimposed on the normal $S_{\text {q }}$ current system centred at $20^{\circ}$ dip latitude, during a partial equatorial counter electrojet day.

Onwumechilli et al. (1973) showed a close relationship between the equatorial electrojet and polar magnetic variations on a day to day basis. Rastogi et al. (1994) showed that the seasonal variation of the daily range of $H$ shows equinoctial maxima at Trivandrum, Kodaikanal and Annamalainagar and slowly vanishes at stations further north. It was suggested that the equatorial stations are affected by the imposition of east-west electric field in addition to that generated by the dynamo action of the earth's ionosphere. Thus, the equatorial electrojet current is far more complex than the picture accepted after the understanding of the abnormal electric conductivities.

Chandra et al. (1971) observed equinoctial maxima in ionospheric drift speed at an equatorial station Thumba, similar to that seen in the range of $H$. Similar equinoctial maxima have been reported in the vertical $F$-region drifts at Jicamarca by Fejer et al. (1979) and at Thumba (Vikramkumar et al., 1984). Rastogi et al. (1994) showed that it is the semi-annual wave in $S_{\mathrm{q}} H$, which is enhanced over the magnetic equator in the same way as the solar diurnal range of $H$ itself. The seasonal variation of $\Delta H$ at non electrojet stations shows predominantly an annual wave with a maximum around summer months.

The current intensity in the ionosphere depends on the ionisation density as well as on the electric field. The daily, seasonal or solar cycle variation of the $S_{\mathrm{q}} H$ could be primarily due to one of these parameters or due to the simultaneous effects of both. The relative roles of these two parameters cannot be estimated from the observations of only the geomagnetic field. Using the simultaneous observations of the maximum $E$-region electron density, $N_{\mathrm{m}} E$, and $\Delta H$ at Indian observatories, Rastogi (1993) showed that the solar cycle variation of $\Delta H$ at low latitudes is contributed primarily by the corresponding variation of $N_{\mathrm{m}} E$, the electric field remaining fairly constant. The seasonal variation of $\Delta H$ is contributed primarily by the corresponding variation of electric field. The daily variation of $S_{q} H$ at an electrojet station is due to the combined effect of the daily variations of the electric field and $E$ layer ionisation. Extending similar analysis Rastogi (1996a) suggested that the electric field is larger in the American than in the Indian region.

The establishment of a rocket launching station near the magnetic equator in India enabled Indian scientists to obtain direct observations of the equatorial electrojet current. In this paper we have attempted to combine rocket and ground based data to derive some new information about the variations of the equatorial electrojet current.

\section{Solar Diurnal Variation of $\boldsymbol{H}$}

First of all we describe in Fig. 1 the quiet day solar daily variations of the northward field $(\Delta X)$ at the equatorial stations Huancayo (HUA), Koror (KOR), Trivandrum (TRD) and Addis-Ababa (ADB) during the three Lloyd seasons of the year 1958. The features common to all stations are (1) the midday value of $\Delta X$ is largest during the $E$-months and least during the local winter, (2) $\Delta X$ continues to increase rapidly after the sunrise to reach a peak at $1100-1200 \mathrm{hr}$ almost in a linear progression, and (3) the decrease of $\Delta X$ in the afternoon is gradual and continues even after the sunset. These features are in conformity with those described earlier by Rastogi and Iyer (1976). Some of the features differing with stations are (1) $\Delta X$ at Huancayo during $E$ and $J$ months continues to increase from the midnight to sunrise when there is no solar radiation, (2) at Addis-Ababa, $\Delta X$ continues to decrease significantly from the midnight to sunrise. Takeda et al. (1986) simulated the ionospheric currents assuming a constant mode tidal winds and IRI model for electron density. They showed that nocturnal currents are not negligible during high solar activity. Rastogi et al. (1996b) had also shown that the night-time variations of $\Delta H$ at Huancayo during different seasons compared very well with the corresponding variations of the electric field derived from the $E$-region horizontal and $F$-region vertical drifts at Jicamarca. It is still a question as to what are the 


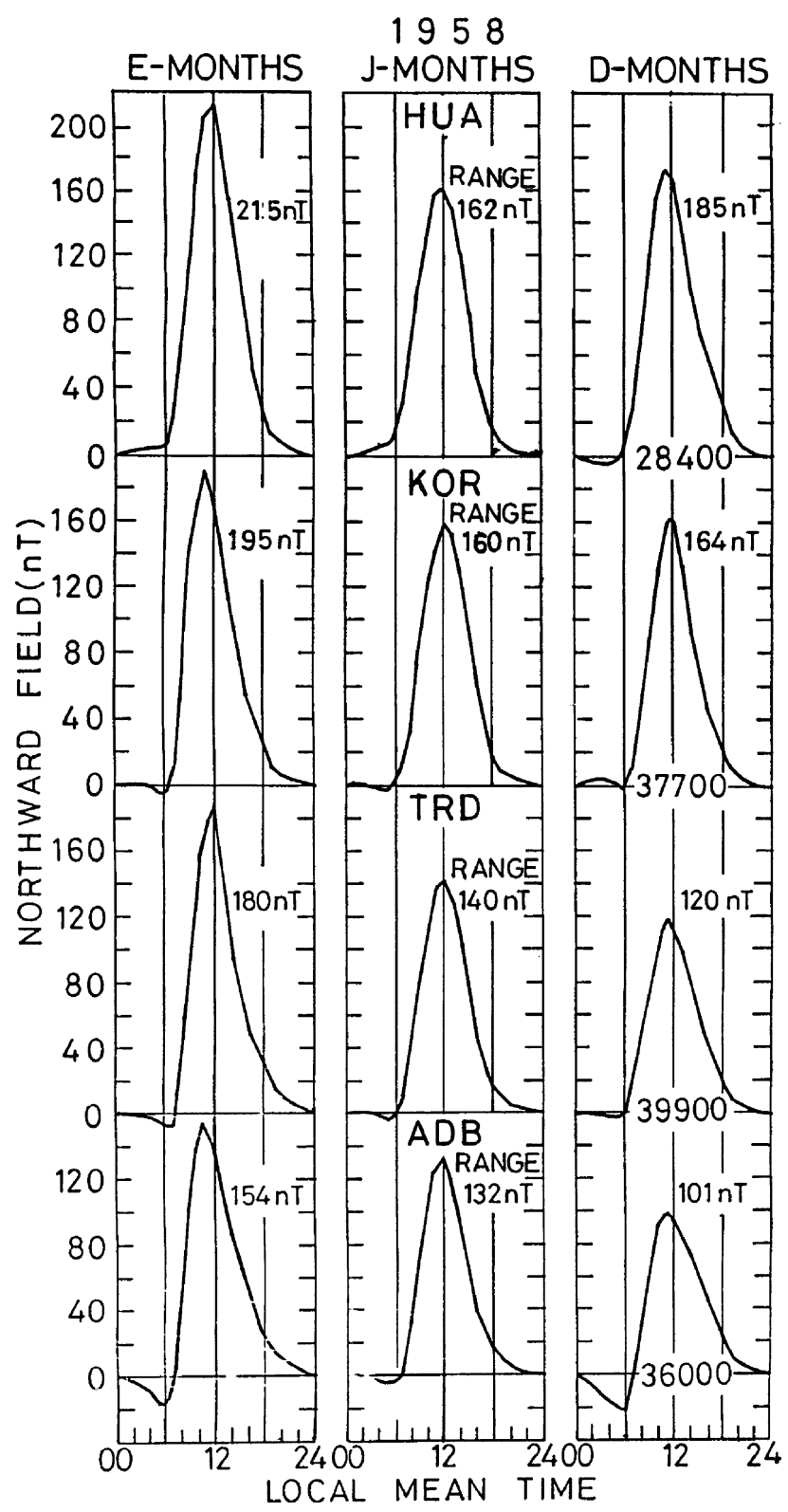

Fig. 1. Daily variations of $\Delta H$ at Huancayo (HUA), Koror (KOR), Trivandrum (TRD) and Kodaikanal (KOD) during different seasons of 1958.

sources of these night-time electric fields.

The daily range in $H$ is usually defined with midnight value or a mean of few hours around midnight as the base value. Due to the changes of few nT in the night time as seen in the daily variations described here one has to consider the overall implications when comparing the data at different stations or different epochs.

\section{Latitudinal Variation of the Daily Range of $\boldsymbol{H}$}

Figure 2 shows the variation of the mean solar daily range of $H$ with dip angle for equatorial stations during the IGY/IGC period (Rastogi, 1964). The names of the stations and the values of the mean horizontal component of the geomagnetic field (in units of $1000 \mathrm{nT}$ ) are also indicated in the figure. The latitudinal variations can be obtained only for the longitude regions around $75^{\circ} \mathrm{W}$ (Peru) and around $75^{\circ} \mathrm{E}$ (India). The $\Delta H$ values in the American

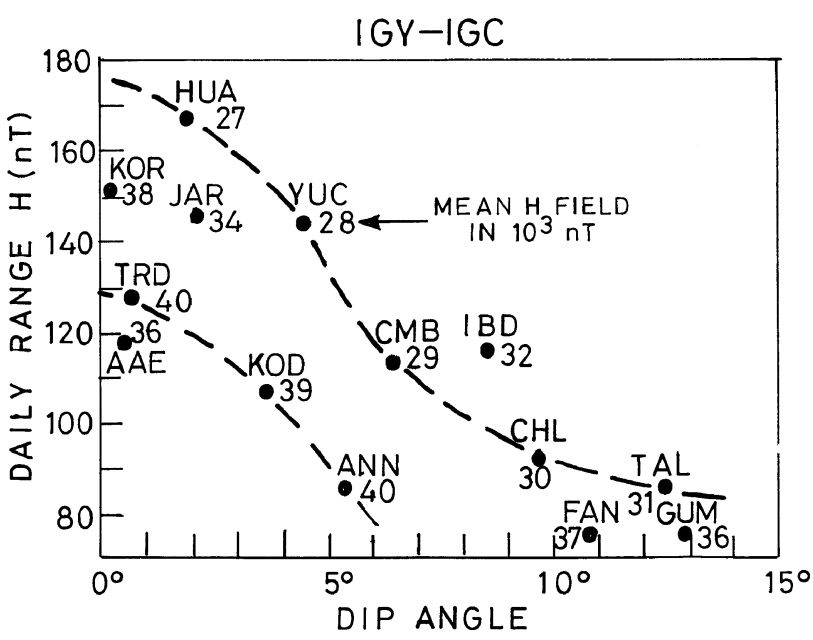

Fig. 2. Daily range in $H$ at low latitude stations plotted as a function of dip angle during IGY/IGC (after Rastogi, 1964).

sector are invariably larger than at corresponding latitude in the Indian region. This was first explained by Rastogi (1962b) as due to the fact that the mean $H$ field was 40,000 $\mathrm{nT}$ in India and about 28,000 nT in Peru. There are few exceptions to this however. At Addis-Ababa where the $H$ field was $36075 \mathrm{nT}$ the range of $H$ is smaller than at Trivandrum with mean value of $H$ of $39896 \mathrm{nT}$. It is also to be noted that the two stations are separated by only three hours in longitude. Also the range in $H$ at Ibadan is significantly larger than the corresponding value at Chimbote and Chiclayo having the same magnetic inclination.

For a comparative study of the electrojet range over the magnetic equator in the American and Indian longitudes, we have to extrapolate the range $H$ at Huancayo and Kodaikanal to the values over the magnetic equator in their respective longitudes. In the plots shown in Fig. 2, the range $H$ has been extrapolated at the dip equator for both the longitude sectors. The daily range in $H$ at Huancayo was $167 \mathrm{nT}$ while the extrapolated value over the equator was $176 \mathrm{nT}$ with a correction factor of 1.05 . Similarly the daily range at Kodaikanal was 107 nT while the extrapolated value over the magnetic equator was 129 $\mathrm{nT}$. Thus the correction factor for Kodaikanal was 1.21. The ratio of range at Huancayo to that at Kodaikanal (1.56) has therefore to be multiplied by 0.87 for extrapolation to the magnetic equators in the respective regions. The ratio of range $H$ at the magnetic equator in the two longitude sectors therefore reduces to 1.36 . The factor of 0.87 has to be kept in mind while comparing the longitudinal effects in the electrojet in the American and Indian sectors using observed data at Huancayo and Kodaikanal.

Using the equatorial electrojet data from the POGO satellite, Cain and Sweeney (1973) noted significant departures from the accepted fact that the range $H$ is inversely proportional to the background $H$ field. They observed that the amplitudes $\Delta H$ over the longitude range $50-90^{\circ} \mathrm{W}$ averaged $60 \%$ higher than elsewhere as expected due to weaker main field but the expected minimum in 
East Asia was not evident. Onwumechilli and Agu (1981) noted that the total eastward current had the main maximum at $280^{\circ} \mathrm{E}$ longitude and a subsidiary maximum at $160^{\circ} \mathrm{E}$ and $230^{\circ} \mathrm{E}$. These features suggest that the strength of the electrojet may be inversely related to the main field and there are significantly large regional differences in this hypothesis.

\section{Solar Cycle Variations of the Electrojet Current}

To study the long term changes in electrojet at Kodaikanal and Huancayo, the annual mean daily variations of $H$ for the years 1954-64 were subjected to harmonic analysis and the amplitudes $\left(A_{1}, A_{2}\right)$ and the times of maximum $\left(T_{1}, T_{2}\right)$ of the diurnal and semi-diurnal components have been computed. The daily variations are based on the mean of five international quiet days for each month. It is well known that the diurnal component of the range in $H$ in the electrojet region remains unchanged during counter electrojet days however the semi-diurnal component undergoes drastic changes on such days (Somayajulu, 1988). A non-electrojet station like Alibag

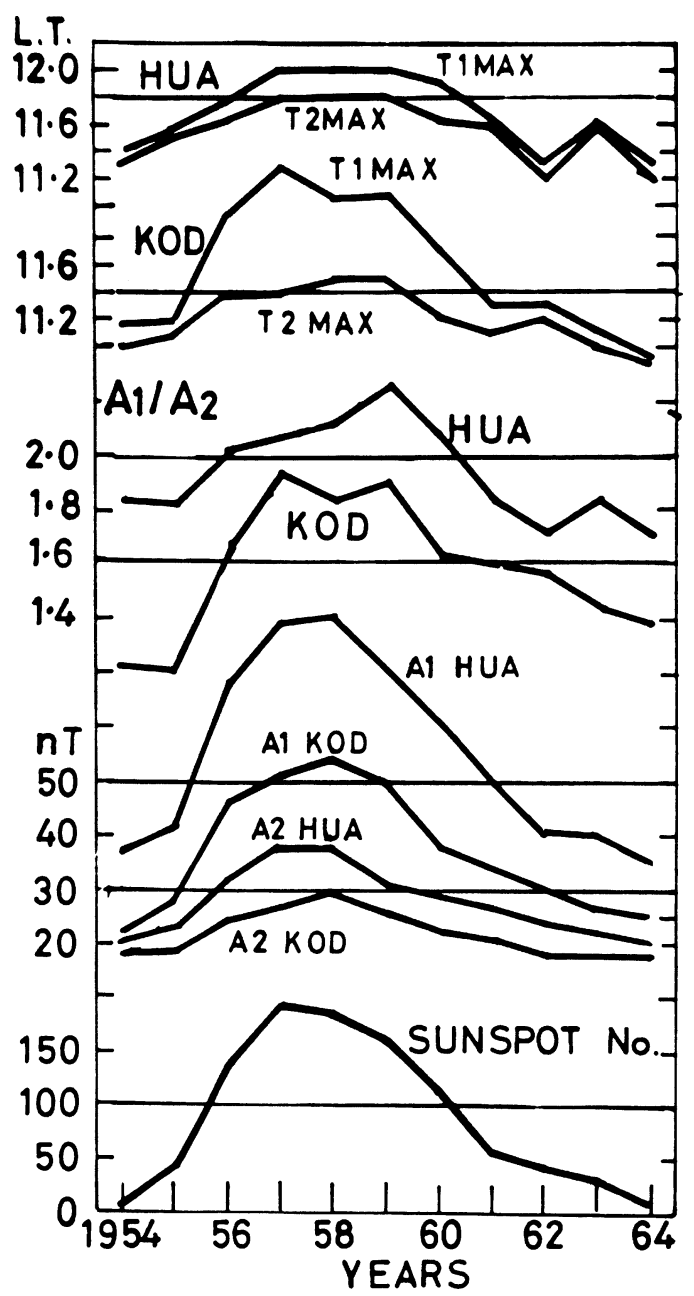

Fig. 3. Solar cycle variations of the amplitude and times of maximum deviations of the diurnal $\left(A_{1}\right)$ and semidiurnal $\left(A_{2}\right)$ components of the annual mean solar daily variations of $\Delta H$ at Huancayo (HUA) and Kodaikanal (KOD). does not exhibit such differences. Further the roles of the neutral winds and solar radiation will determine the shapes of the daily variations in $H$. Figure 3 shows the solar cycle variations of these parameters for the annual mean variations of $H$ field at Huancayo and Kodaikanal. It is seen that both the diurnal and semi-diurnal amplitudes at Huancayo as well as at Kodaikanal vary faithfully with the sunspot number. During any of the years the amplitude $A_{1}$ or $A_{2}$ is larger at Huancayo than at Kodaikanal. The ratio $A_{1} / A_{2}$ at Kodaikanal varies from 1.2 during low to 1.9 during high sunspot years. Correspondingly the ratio $A_{1} /$ $A_{2}$ at Huancayo varies from 1.8 to 2.2 from low to high sunspot years. The variations of the amplitudes $A_{1}$ and $A_{2}$ with sunspot number can be quantitatively expressed by the equation

$$
A_{i}=a_{i}\left(1+b_{i} R z\right)
$$

and the resultant expressions are given below

$$
\begin{aligned}
& A_{1}(\mathrm{KOD})=22(1+0.0072 R) \mathrm{nT} \\
& A_{1}(\mathrm{HUA})=33(1+0.0074 R) \mathrm{nT}, \\
& A_{2}(\mathrm{KOD})=16(1+0.0041 R) \mathrm{nT}, \\
& A_{2}(\mathrm{HUA})=20(1+0.0043 R) \mathrm{nT} .
\end{aligned}
$$

It is seen that the value of $A_{1}$ at Huancayo is 1.5 times the value at Kodaikanal. The value of $A_{2}$ at Huancayo is 1.25 times the value at Kodaikanal. Further the value of $b_{1}$ at Kodaikanal or at Huancayo is about 0.007 while the value of $b_{2}$ at both the stations is about 0.004 . This shows that the diurnal component of the equatorial electrojet is significantly more important than the semi-diurnal component.

The time of maximum of the diurnal component varies from 11.3 to $12.0 \mathrm{hr}$. LT at for Huancayo with the variation of the solar activity. For the semi-diurnal component the variation is from 11.2 to $11.8 \mathrm{hr}$. LT. This causes the daily peak of $\Delta H$ to occur nearer to the noon during high solar activity years. At Kodaikanal the time of maximum of the semi-diurnal component varies from 11.0 to $11.5 \mathrm{hr}$. LT with the variation of solar activity. However the time of maximum of the diurnal component, $\mathrm{T} 1$, varies from 11.2 to $12.3 \mathrm{hr}$. LT from minimum to maximum solar activity. The delaying of the time of maximum with increasing solar activity is in conformity with the earlier results of Rastogi and Iyer (1976). Patel and Rastogi (1978) have made a detailed study of the coefficients of diurnal and semi-diurnal components in the solar daily variations of $H$ at Huancayo and Trivandrum. They showed that the semidiurnal component $a_{2}$ is greater at Huancayo than at Trivandrum during the months of September to March while during April to August the amplitude $a_{2}$ is larger at Trivandrum than at Huancayo. The diurnal component $a_{1}$ is larger at Huancayo than at Trivandrum during any of the months of the year. Thus whereas $a_{2}$ is affected by the local season, being larger during local summer months; the amplitude $a_{1}$ is maximum at any longitude during equinoxes and for any particular month it is larger in the American than in the Indian longitudes. The importance of the solar diurnal component points to the role of the 


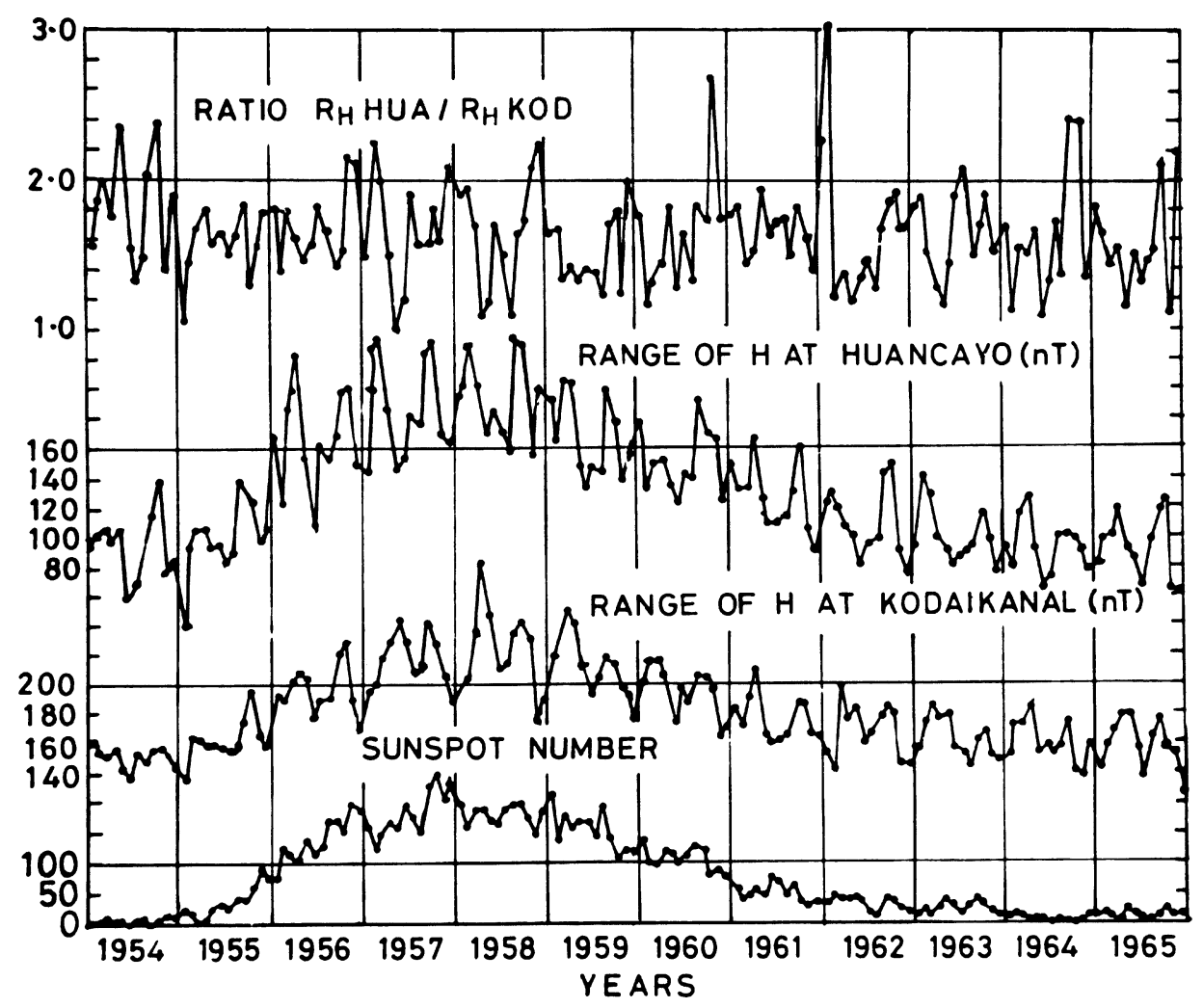

Fig. 4. Month to month variations of the monthly mean values of the sunspot number, $S_{\mathrm{q}}$ range of $H$ at Huancayo and Kodaikanal as well as the ratio of range at Huancayo and Kodaikanal for the period 1954 to 1965.

solar thermal tides to have a major role in the atmospheric dynamics.

A closer scrutiny of the coefficients $a$ and $b$ shows that the values of coefficient $b$ are practically the same at both Kadaikanal and Huancayo. This means that the longitudinal inequality in the equatorial electrojet exists during the quietest periods of the solar activity. With the rise of solar activity the ranges at the two stations increase in same proportion. Thus the source of the inequality remains the same for different epochs. It is to be ascertained that the solar activity effects in the equatorial electrojet are due to the electrical conductivity and one needs other ionospheric data to answer these questions. The solar activity recorded its minimum during 1954, maximum in 1958 and back to another minimum in 1964. The solar cycle variations of range of $H$ at Huancayo as well as Kodaikanal following the variations of the sunspot numbers is very clear at least on an annual basis.

The magnitude of the electrojet current is generally identified as the solar daily range of the $H$ field, $R_{\mathrm{H}}$, at an electrojet station. In Fig. 4 are shown the average month to month variations of $R_{\mathrm{H}}(\mathrm{HUA}), R_{\mathrm{H}}(\mathrm{KOD})$ and the ratio $R_{\mathrm{H}}(\mathrm{HUA}) / R_{\mathrm{H}}(\mathrm{KOD})$. The seasonal variations of $R_{\mathrm{H}}(\mathrm{HUA})$ and $R_{\mathrm{H}}(\mathrm{KOD})$ show clearly the equinoctial maxima during any solar epoch year. The ratio $R_{\mathrm{H}}(\mathrm{HUA}) / R_{\mathrm{H}}(\mathrm{KOD})$ varied from 1.0 to 3.0 on individual months and does not indicate any systematic variation with solar cycle. The ratio seems to be larger during December when it is summer at Huancayo and winter at Kodaikanal. It is clearly seen that in spite of large equinoctial maxima in the seasonal variations of the ranges, the ratio does not show any semiannual wave. It has a maximum value of 1.9 during December-January and a minimum value of 1.4 around April. The annual average value of $R_{\mathrm{H}}(\mathrm{HUA}) / R_{\mathrm{H}}(\mathrm{KOD})$ is 1.63. Normalised to the magnetic equator at the respective longitudes the ratio of diurnal range in American to Indian zones comes to $1.63 \times 0.90=1.47$.

\section{Ionospheric Drift Observations of Equatorial Electrojet}

With the establishment of an equatorial rocket launching station at Thumba in India an ionospheric research station was set up. Many important results came out from the ionospheric drift measurements made at Thumba during 1964-69 using the spaced receiver method of Mitra (1949). The drifts were found to be westward during daytime and eastward during nighttime (Deshpande and Rastogi, 1966, Chandra and Rastogi, 1970). A high correlation between the drift speed and the range in $H$ was established later and thus the drift measurements provided an excellent means of monitoring the equatorial electric field (Chandra et al., 1971). Some new results on equatorial electrojet and counter electrojet, especially during geomagnetic periods were obtained by combining the drift data with the ground measurement of geomagnetic field. The occasional depressions in $H$ (below the night level) were found to be associated with the reversal of the electric field and the disappearance of the ionospheric $E$-region irregularities (Rastogi et al., 1971).

One rather unexpected result obtained from the long 


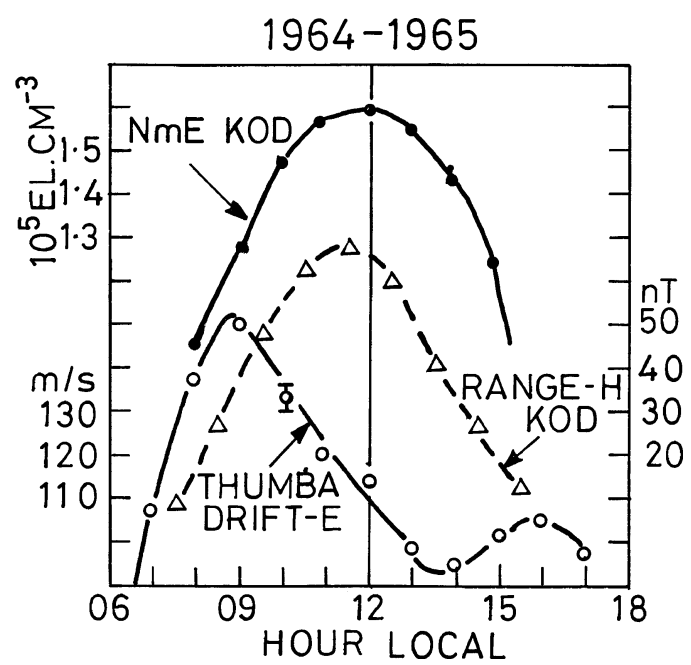

Fig. 5. The daily variations of the $E$-region drift (eastward) over Thumba, range in $H$ at Kodaikanal and the maximum $E$-region electron density over Kodaikanal averaged over the years 1964-65.

series of drift observations at Thumba was that the peak drift speed occurred around 09-10 LT, which is earlier than the time of peak $E$-region electron density at $12 \mathrm{LT}$. Figure 5 shows the mean daily variations of the $E$-region drift speed at Thumba, range in $H$ at Kodaikanal and the maximum $E$-region electron density, $N_{\mathrm{m}} E$ averaged over the years 1964-65. It must be noted that while the daily variation of $H$ is based on five quiet days, that of $N_{\mathrm{m}} E$ is based on monthly mean values. The daily variation of the drift speed is based on large number of observations (minimum of 200 at any hour) and a typical value of the standard error in mean is also indicated in the figure (about 2\%). The observed daily variation of the drift speed explained for the first time the peak in $\Delta H$ occurring before noon $(11 \mathrm{LT})$. This is because of the fact that $\Delta H$, results due to the combined effects of the electron density and the electric field which peak at $12 \mathrm{LT}$ and around 09$10 \mathrm{LT}$ respectively. VHF radar measurements of the $F$ region vertical drift velocity over Jicamarca, in the American longitude sector, also show daytime peak between 09 and 11 LT (Fejer et al., 1979).

The solar activity for the period 1964 to 1969 varied from a flux (at $2800 \mathrm{MHz}$ ) of 70 units to 140 units. The mean drift speed in the $E$ or $F$ region did not show any significant change (Misra et al., 1971). It was concluded that the ionospheric electric field over the magnetic equator probably remains constant with the solar cycle and the observed variations of the electrojet strength are due to the corresponding change of $E$ region electron density and hence of $E$ region electric conductivities. There are not many $E$-region measurements made from Jicamarca however the vertical $F$-region drift measurements over Jicamarca also showed that daytime drifts are usually larger during low sunspot years (Fejer et al., 1979).

One of the very first rocket-borne experiments in India had been the detection and measurement of the altitude profile of the electrojet current by means of proton precession magnetometers. The results of these

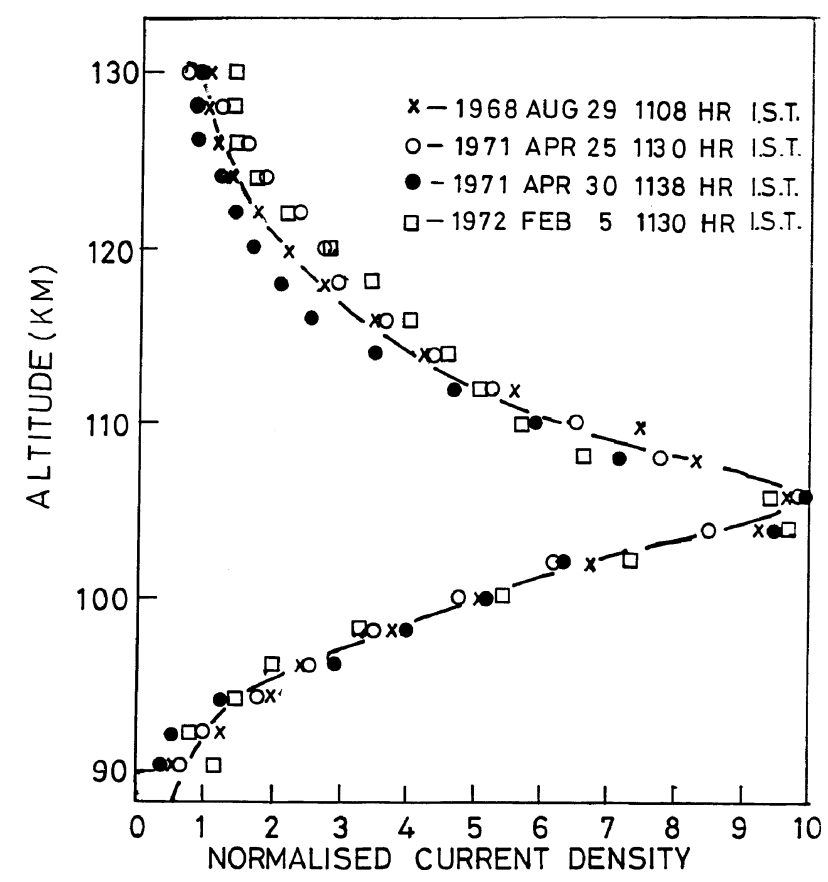

Fig. 6. The vertical distribution of the equatorial electrojet current density measured during four midday flights from Thumba, plotted after normalizing the peak current densities to $10 \mathrm{Amp} . \mathrm{km}^{-2}$. The full line shows the average distribution (after Sampath and Sastry, 1979a).

observations have been consolidated in a series of papers by Sampath and Sastry $(1979 a, b)$. It was found that the maximum value of the ionospheric current was linearly related to the ground measurements of $\Delta H$ at Kodaikanal. When the observed profiles during different rocket flights were plotted with individual peak current normalised to a constant value then the profile of current remained remarkably constant. Figure 6 shows the composite result of four rocket flights conducted around midday hours normalised to the peak current of $10 \mathrm{~A} / \mathrm{km}^{2}$. Thus for a comparative study of the electrojet, $\Delta H$ at ground can be taken as precise indication of the electrojet current in the E-region.

The second series of rocket experiments on the equatorial electrojet studies in India had been the measurements of electron density profiles in the $E$-region using Langmuir probe and the resonance probe (Prakash et al., 1972). Figure 7 shows the superposed altitude profiles of electron density for midday (10-14 h) over Thumba (Subbaraya et $a l ., 1983)$. The date and time of the measurements of the 12 profiles is provided in Table 2. It is seen that in spite of different days of the experiments when the equatorial electrojet current could have been different the electron density profiles were similar. Leaving apart the two profiles with extreme values (which were on counter electrojet days) the electron density at $100 \mathrm{~km}$ altitude differ by only about $\pm 15 \%$. One can conclude therefore that during an epoch of time, in which solar activity did not alter appreciably, $N_{\mathrm{m}} E$ (maximum $E$ region electron density) did not change very much. Therefore the day to day variability in the equatorial electrojet (or in the range of $H$ ) is largely due to the corresponding variations of the electric field. 


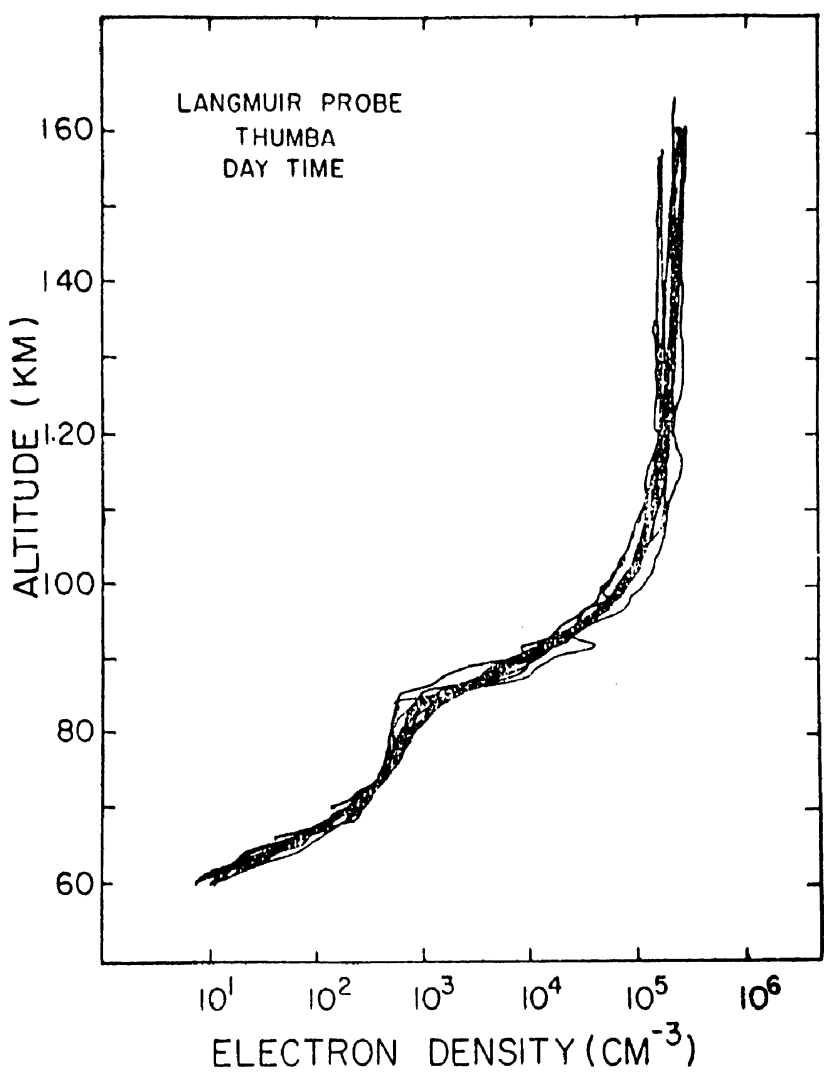

Fig. 7. Mass plot of the electron densities obtained from twelve daytime rocket experiments conducted at Thumba during the period 1966 to 1978 (after Subbaraya et al., 1983).

Table 2. Details of rocket flights conducted from Thumba around midday to measure electron density.

\begin{tabular}{clccr}
\hline Serial No. & Flight Number & Date & Time & $R z$ \\
\hline 1 & N.A. 20.05 & $07-07-66$ & 1345 & 58 \\
2 & N.A. 20.07 & $29-08-68$ & 1415 & 64 \\
3 & N.A. 10.37 & $28-01-71$ & 1040 & 109 \\
4 & N.A. 10.38 & $28-01-71$ & 1110 & 109 \\
5 & N.A. 10.43 & $07-04-72$ & 1230 & 71 \\
6 & N.A. 10.44 & $13-10-72$ & 1229 & 15 \\
7 & N.A. 10.45 & $03-03-73$ & 1220 & 35 \\
8 & Co. 16 & $17-08-72$ & 1532 & 55 \\
9 & Co. 04 & $19-02-75$ & 1105 & 0 \\
10 & Co. 22 & $21-04-75$ & 1341 & 0 \\
11 & Co. 40 & $04-06-77$ & 1120 & 25 \\
12 & P. 159 & $09-02-75$ & 1233 & 22 \\
\hline
\end{tabular}

\section{Variations of Range in $H$ and $E$-region Electron Density}

The solar daily range of $H$ at equatorial station is due to an eastward current in the $E$ region. Rastogi (1993), assuming the currents to be proportional to the product of the conductivity or $N_{\mathrm{m}} E$ and the electric filed $(\xi)$, suggested that the $\Delta H$ at any time $t$, can be given as

$$
\Delta H(t) \propto N_{\mathrm{m}} E(t) \xi(t)
$$

and an index $K$ related to the electric field can be computed by

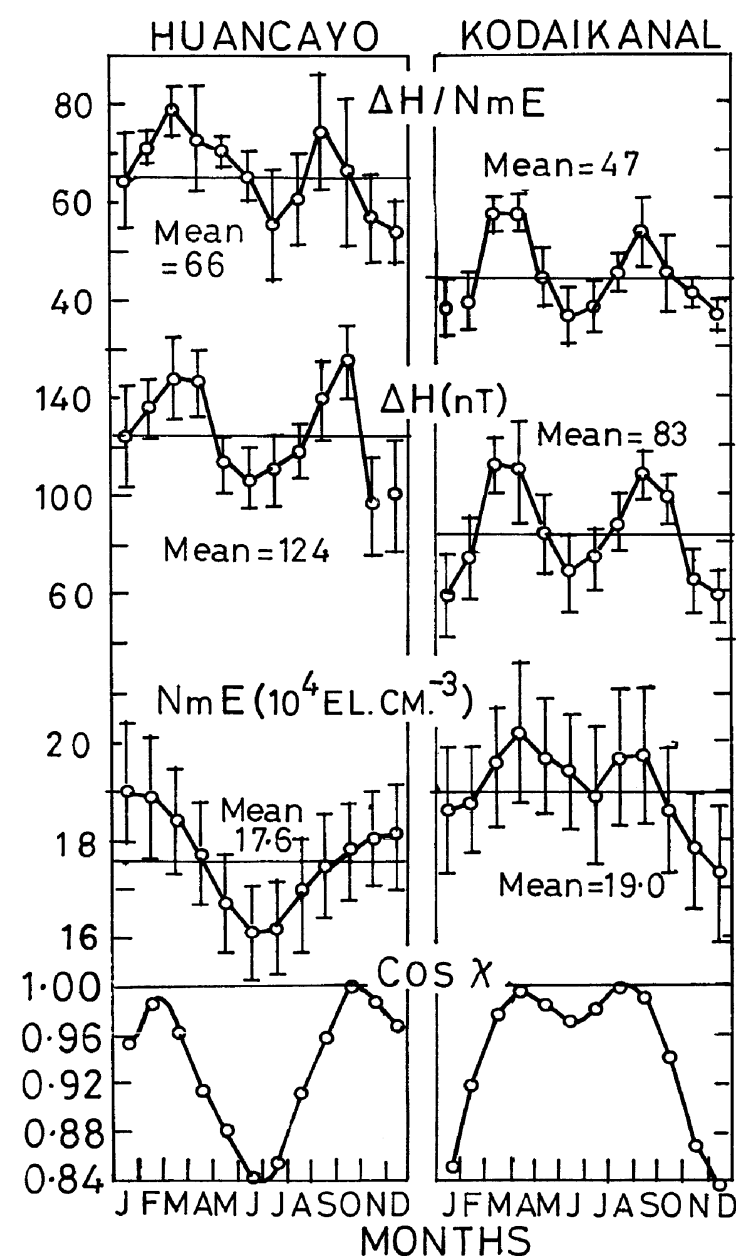

Fig. 8. Mean seasonal variations of the parameters $N_{\mathrm{m}} E, \Delta H$ and $\Delta H /$ $N_{\mathrm{m}} E$ for Huancayo and Kodaikanal averaged over the years 1958-65. Also shown are the seasonal variations of the cosine of the solar zenith angle $(\cos \chi)$ for both the stations.

$$
K=\Delta H(t) / N_{\mathrm{m}} E(t)
$$

Fortunately, for a limited number of years 1958-1966, the parameter $f_{\mathrm{b}} E_{\mathrm{s}}$, which is a measure of the critical frequency of the $E$ layer ( $f_{\mathrm{o}} E$ in $\left.\mathrm{MHz}\right)$ are available at both the stations Huancayo and Kodaikanal. In Fig. 8 we have plotted the mean month to month values of $N_{\mathrm{m}} E, \Delta H$ and $\Delta H / N_{\mathrm{m}} E$ for both Huancayo and Kodaikanal averaged over the years 1958-65. These are also compared with the seasonal variations of the cosine of the solar zenith angle $(\cos \chi)$ for both the stations. It may be recalled that Huancayo is situated at $12.1^{\circ} \mathrm{S}$ and Kodaikanal at $10.2^{\circ} \mathrm{N}$ and hence the seasonal variations of $\cos \chi$ are inverse to each other. The seasonal variations of $N_{\mathrm{m}} E$ at Huancayo and Kodaikanal are very similar to the corresponding variations of the solar zenith angle at the respective places. This is in conformity with the fact that the $E$-layer ionisation density follows very closely the zenith angle of the Sun according to the modified Chapman's law of ionisation in upper atmosphere. The mean value of $N_{\mathrm{m}} E$ is $19.0 \times 10^{4} \mathrm{el} . \mathrm{cm}^{-3}$ at Kodaikanal compared to a value of $17.6 \times 10^{4} \mathrm{el} . \mathrm{cm}^{-3}$ at Huancayo and this seems to be due to the lower geographic latitude of Kodaikanal than of Huancayo. 
The seasonal variations of $\Delta H$ at Huancayo and Kodaikanal show prominent equinoctial maxima. The mean value of $\Delta H$ at Huancayo was $124 \mathrm{nT}$ as compared with a value of $83 \mathrm{nT}$ at Kodaikanal in spite of a higher mean value of $N_{\mathrm{m}} E$ at Kodaikanal than at Huancayo. The seasonal variations of $\Delta H / N_{\mathrm{m}} E$ show distinct equinoctial maxima at Huancayo as well as at Kodaikanal with mean values of 66 and 47 respectively. Richmond (1989) had suggested that the equinoctial maxima in the electrojet current intensity are due to the effect of solar zenith angle. The present results however show that this is not true and the observed variations are due to the equinoctial maxima in the ionospheric electric field at low latitudes itself.

\section{Ground Based and Rocket-Borne Measure- ments of the Electrojet Current}

The measurements of equatorial electrojet current by the fluxgate magnetometer using rocket-borne instruments have been made in India (Maynard and Cahill, 1965; Sastry, 1968). Similar measurements were made in the American sector, off the coast of Peru (Maynard, 1967; Davies et al., 1967; Schuman, 1970). Direct comparison of the electrojet strength in the two longitudes could not be made as these few measurements were made during different epochs of time. Sampath and Sastry (1979a, b) have consolidated the data from the series of observations in India and showed that the peak current measured by the rocket-borne instrument over Thumba varies linearly with the magnitude of $\Delta H$ at Kodaikanal at the same time. A similar comparison has been now made between the rocket measurements of electrojet current in Peru and the amplitude of $\Delta H$ at Huancayo at the time of the rocket experiment (Sinha et al., 1999). Figure 9 shows the relationships between the two parameters for the two longitude sectors. It is seen that for the Western Hemisphere too the peak electrojet current, $J_{\mathrm{m}}$ is linearly related to the ground measurements of $\Delta H$, however the regression lines are different. A change of $100 \mathrm{nT}$ at ground is equivalent to an ionospheric current of $10.2 \mathrm{Amp} \mathrm{km}^{-2}$ for the Indian longitudes and of only $8.4 \mathrm{Amp} \mathrm{km}^{-2}$ for the American longitudes. In other words a current of $10 \mathrm{Amp}$ $\mathrm{km}^{-2}$ in the $E$ region would produce a value of $\Delta H$ of $98 \mathrm{nT}$ in the Indian and of $119 \mathrm{nT}$ in the American longitudes. Comparison of the altitude profiles of current density in the two longitude sectors shows the altitudes of peak current density are at 106 and $108 \mathrm{~km}$ with half widths of 12 and $10 \mathrm{~km}$ respectively at Thumba and Peru (Sinha et al., 1999). Thus the larger value of range in $H$ at Peru could possibly be either due to a greater width of the electrojet along N-S over Peru than over Thumba.

The relationship between $J_{\mathrm{m}}$ and $\Delta H$ is not affected by induction, magnetospheric or any other effects. If we assume that the relationship between $J_{\mathrm{m}}$ and $\Delta H$ remains practically the same during different epochs then the long series of ground measurements of $\Delta H$ in the two longitude sectors can be converted into series of $E$-region current strength $J$. E-region peak electron densities $\left(N_{\mathrm{m}} E\right)$ are also available for certain epoch both at Huancayo and Kodaikanal. The electron velocity $V\left(\mathrm{~ms}^{-1}\right)$ can be calculated using the equation

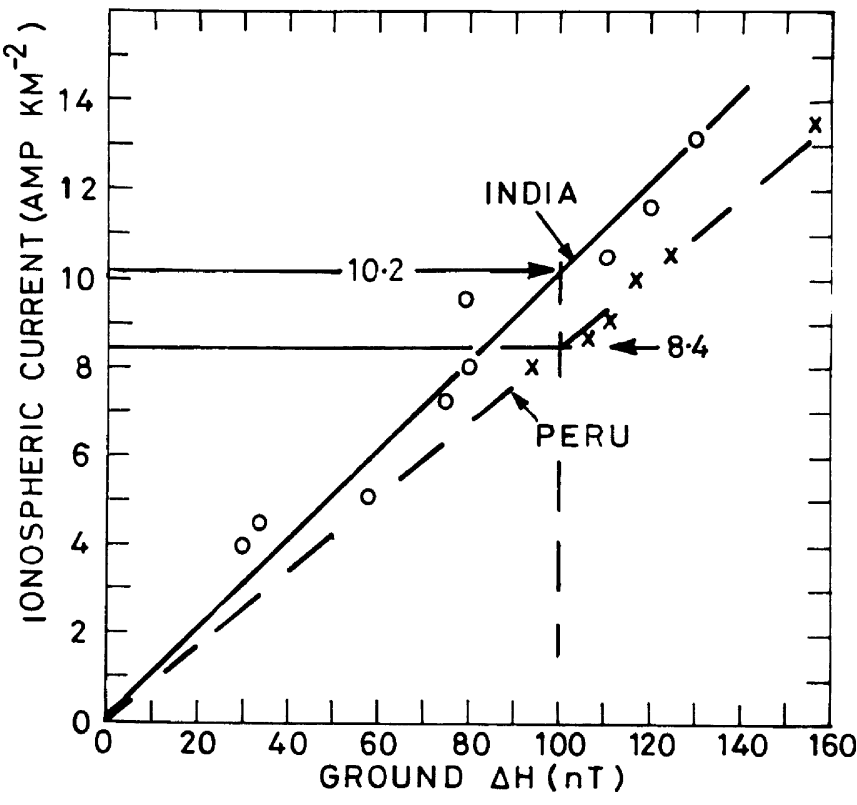

Fig. 9. Relationship between the peak current density in ionosphere as measured by rocket-borne measurements in India and Peru and $\Delta H$ measured at ground at same time.

$$
J=N \cdot e \cdot V
$$

Where $N$ is the electron density $\left(\mathrm{m}^{-3}\right), e$ is the electronic charge (Coulumb) and $J$ is the current $\left(\mathrm{Amp} \mathrm{m}^{-2}\right)$. The month to month variations of the peak electron density $N_{\mathrm{m}} E$ at midday, current density $J$ and the electron velocity $V_{\mathrm{E}}^{\mathrm{m}}$ over Huancayo and Kodaikanal are shown in Fig. 10 for the years 1958-1965. The ratios of the values at Huancayo to that at Kodaikanal are also plotted in the figure. From the figure it is seen that all the parameters $N_{\mathrm{m}}$, $J$ or $V_{\mathrm{E}}$ show very distinct solar cycle variations. The ratio $N_{\mathrm{m}}(\mathrm{HUA}) / N_{\mathrm{m}}(\mathrm{KOD})$ shows consistent and similar seasonal variation year after year with a minimum around June and maximum around December months. This confirms the earlier conclusion that the $E$ region peak electron density strictly follows the law $N_{\mathrm{m}} \propto \cos ^{\eta} \chi$ (Rastogi, 1958)

The current density $J$ does not follow the seasonal variation of $N_{\mathrm{m}}$ as would be expected if the conductivity was the main controlling factor for $J$. However distinct semi-annual waves are seen during any of the years. The ratio of the current over Huancayo to over Kodaikanal, $J_{\text {(HUA/KOD) }}$, varies between 1.0 and 1.5 in general with highest values around December solstice. The estimated electron velocity, $V_{\mathrm{E}}$ also show distinct equinoctial maxima at both the stations. However the values are much larger over Huancayo than over Kodaikanal especially during high sunspot years. The $V_{\mathrm{E}}$ over Huancayo show clear solar cycle variation with values exceeding $400 \mathrm{~m} / \mathrm{s}$ during high sunspot years and between 250 to $400 \mathrm{~m} / \mathrm{s}$ during low sunspot years. The ratio $V_{\mathrm{E}(\mathrm{HUA} / \mathrm{KOD})}$ varies between 1.0 and 2.0 with no clear seasonal variation.

The mean seasonal variations of the current density $J$ and velocity $V_{\mathrm{F}}$ for Huancayo and Kodaikanal averaged over the years 1958-65 are shown in Fig. 11. The current density $J$ shows semi-annual variations with equinoctial 


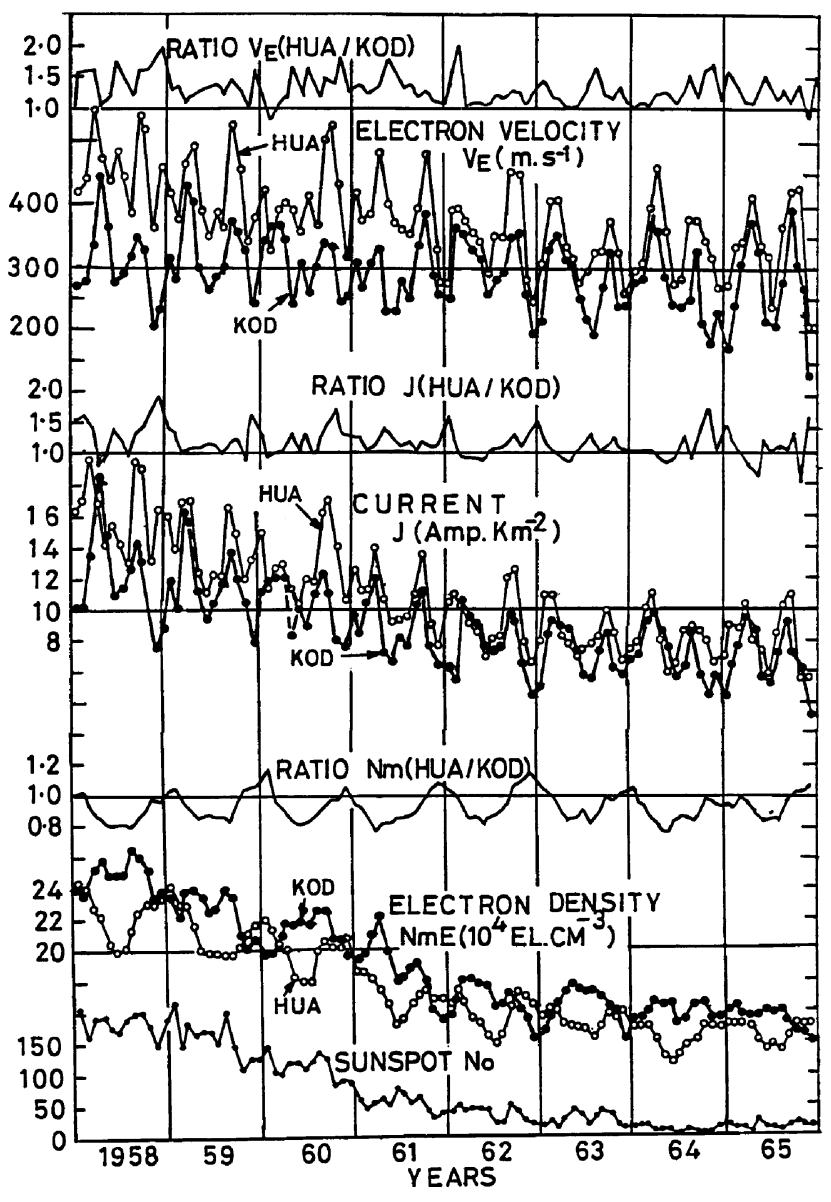

Fig. 10. Month to month variations of the midday values of the E region electron density $\left(N_{\mathrm{m}} E\right)$, estimated ionospheric current density $(\mathrm{J})$ and the estimated horizontal electron velocity $\left(V_{\mathrm{E}}\right)$ at Huancayo (HUA) and Kodaikanal (KOD) for the epoch 1958-65 compared with corresponding variation of the sunspots. The ratio of these parameters (HUA/KOD) are also shown in the figure.

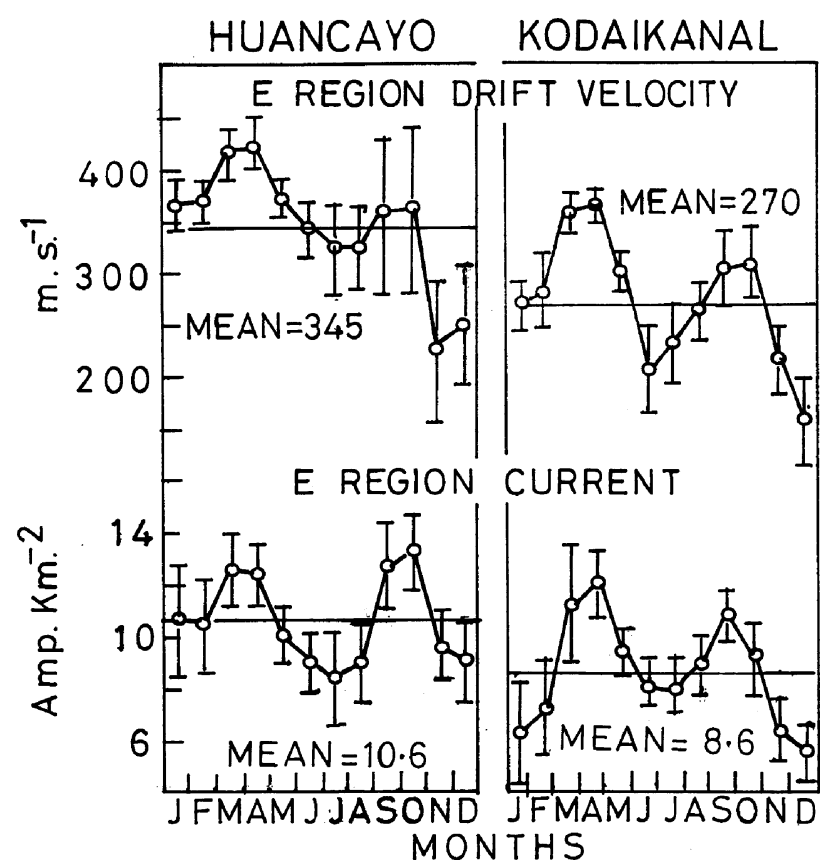

Fig. 11. Mean seasonal variations of the estimated current density and electron velocity over Huancayo and Kodaikanal averaged over the years 1958-65.

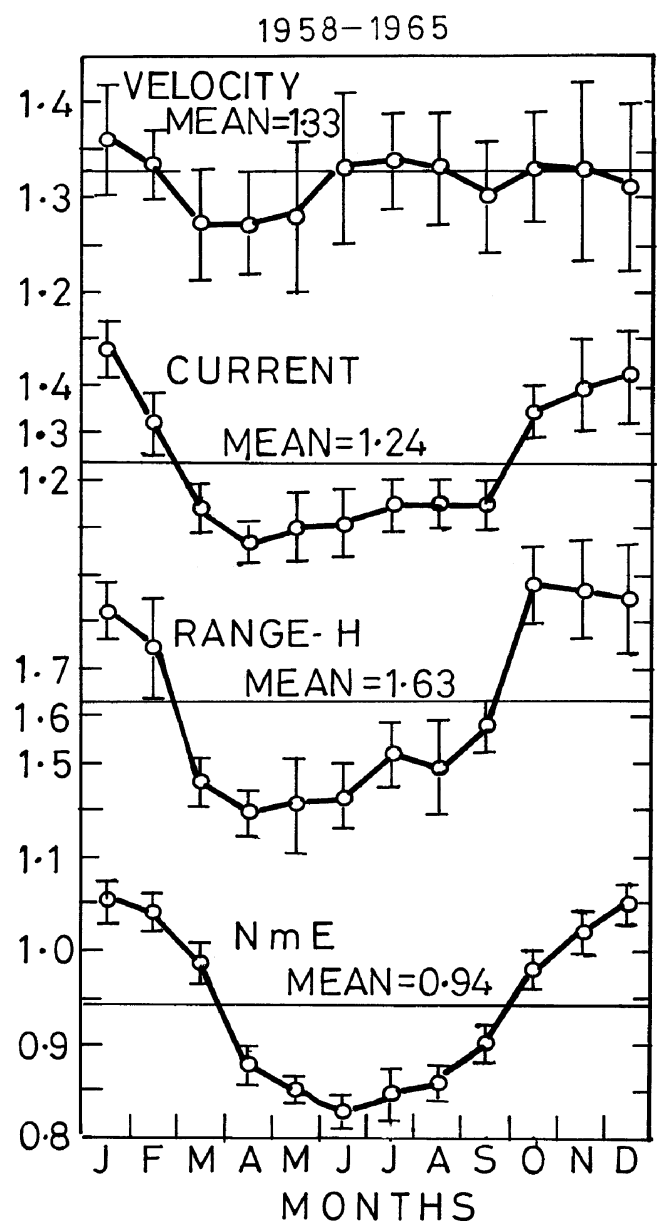

Fig. 12. Mean seasonal variations of the ratios of the values over Huancayo to that at over Kodaikanal for the parameters $N_{\mathrm{m}} E, \Delta H, J$ and $V_{\mathrm{E}}$ averaged over the years 1958-65.

maxima at both the stations. The average values are 10.6 Amp $\cdot \mathrm{km}^{-2}$ for Huancayo and $8.6 \mathrm{~km}^{-2}$ for Kodaikanal. The drift velocity also shows clear equinoctial maxima with average values of $345 \mathrm{~m} / \mathrm{s}$ and $270 \mathrm{~m} / \mathrm{s}$ respectively over Huancayo and Kodaikanal.

Finally we show the seasonal variations of the ratios of values at Huancayo and Kodaikanal for the parameters $N_{\mathrm{m}} E, \Delta H, J$ and $V_{\mathrm{E}}$ averaged over the epoch 1958-65 in Fig. 12. The ratio of $N_{\mathrm{m}} E$ shows clearly an annual wave with values varying from 1.05 in December-January to 0.85 in June with a mean value of 0.94 . The ratio of $\Delta H$ varies from about 1.85 during December-January to about 1.4 during June with a mean value of 1.63 . The ratio in $J$ varies from about 1.4 in December-January to about 1.1 during June with a mean value of 1.24 . The ratio in $V_{\mathrm{E}}$ does not show a clear seasonal variation however and has mean value of 1.33 .

\section{Conclusion}

The present analysis has shown that when corrections are made for the solar zenith angle variation with month, the seasonal variation of electrojet current maximises during equinoctial months. At other low latitude stations $\Delta H$ is maximum around summer months. This clearly indicates an additional non-solar radiation source for the 
equatorial electrojet current. Further it is observed that whereas the range in $H$ is $63 \%$ higher at Huancayo on an average, the inequality in current density $J$ is only $24 \%$. The contribution to this inequality due to the electron density is small $(6 \%)$ and that too in opposite sense with the value larger at Kodaikanal than at Huancayo. Therefore the longitudinal inequality is caused primarily by an increase in velocity $V_{\mathrm{E}}$ which is $33 \%$ higher over Huancayo than over Kodaikanal.

It is concluded that the horizontal electric field in the ionosphere ( $E$-region) over the magnetic equator is larger in the American than in the Indian sector. The identification of this additional source of the field would greatly help in understanding many other complex problems of the equatorial electrojet.

\section{References}

Broun, J. A., Trivandrum magnetic observations Vol. I, 576 pp., Henry S. King and Co., London, 1874

Cain, J. C. and R. E. Sweeney, The POGO data, J. Atmos. Terr. Phys., 35, 1271-1247, 1973.

Chandra, H. and R. G. Rastogi, Daily variation of $F$-region drifts at Thumba, J. Atmos. Terr. Phys., 32, 1309-1311, 1970.

Chandra, H., R. K. Misra, and R. G. Rastogi, Equatorial ionospheric drift and the electrojet, Planet. Space Sci., 19, 1497-1503, 1971.

Chapman, S., The equatorial electrojet as detected from the abnormal electric current distribution above Huancayo, Peru and elsewhere, Arch. Meteorol. Geophys. Bioclimatal, A4, 368-390, 1951.

Chapman, S. and K. S. Rajarao, The $H$ and $Z$ variations along and near the equatorial electrojet in India, Africa and the Pacific, J. Atmos. Terr. Phys., 27, 559-581, 1965.

Davies, T. N, K. Burrows, and J. D. Stolarik, A latitude survey of the equatorial electrojet with rocket-borne magnetometers, J. Geophys. Res., 72, 1845-1861, 1967.

Deshpande, M. R. and R. G. Rastogi, Ionospheric horizontal drifts within the equatorial electrojet region in India, Ann. Geophys., 22, 418-421, 1966.

Egedal, J., The magnetic diurnal variation of the horizontal force near the magnetic equator, Terr. Magn. Atmos. Electr., 52, 449-451, 1947.

Fejer, B. G., D. T. Farley, R. F. Woodman, and C. Calderon, Dependence of the equatorial $F$-region vertical drifts on season and solar cycle, $J$. Geophys. Res., 84, 5792-5796, 1979.

James, M. E., D. Tripathi, and R. G. Rastogi, Day to day variability of ionospheric current system, Ind. J. Radio \& Space Phys., 25, 36-43, 1996.

James, M. E., R. G. Rastogi, and D. R. K. Rao, Identification of the current system associated with a partially reversed equatorial electrojet, J. Geomag. Geoelectr., 49, 633-640, 1997.

Kane, R. P., Relationship between $H$ ranges at equatorial and middle latitudes, J. Atmos. Terr. Phys., 33, 319-327, 1971.

Maynard, N. C., Measurements of ionospheric currents off the coast of Peru, J. Geophys. Res., 72, 1863-1875, 1967.

Maynard, N. C. and L. J. Cahill, Measurement of the equatorial electrojet over India, J. Geophys. Res., 70, 5923-5936, 1965.

Misra, R. K., H. Chandra, and R. G. Rastogi, Solar cycle effects in the electron drifts over the magnetic equator, J. Geomag. Geoelectr., 23, 181-186, 1971

Mitra, S. N., A radio method of measuring winds in the ionosphere, Proc. IEEE, 96, 441-446, 1949.

Onwumechilli, C. A. and C. E. Agu, Longitudinal variation of equatorial electrojet parameters derived from POGO satellite observations, Planet. Space Sci., 29, 627-634, 1981.

Onwumechilli, C. A., A. K. Kawasaki, and S.-I. Akasofu, Relationship between the equatorial electrojet and the polar magnetic variations, Planet. Space Sci., 21, 1-16, 1973.

Osborne, D. G., Correlations between quiet-day magnetic ranges, $J$. Atmos. Terr. Phys., 28, 45-51, 1966.
Patel, V. P. and R. G. Rastogi, On the solar control of the quiet day geomagnetic variations near the magnetic equator, Curr. Sci., 47, 325-327, 1978.

Prakash, S., B. H. Subbaraya, and S. P. Gupta, Rocket measurements of ionization Irregularities in the equatorial ionosphere at Thumba and identification of plasma Instabilities, Ind. J. of Radio \& Space Phys., 1, 72-80, 1972.

Rastogi, R. G., A study of the noon critical frequencies of the $E$ and $F_{1}$ layers of the ionosphere, Geofisica Pura Appl. (Milano), 40, 145$156,1958$.

Rastogi, R. G., Enhancement of the lunar tide in the noon critical frequency of the $F_{2}$ Layer over the magnetic equator, J. Res. (NBS), 66D, 601-606, 1962a.

Rastogi, R. G., Longitudinal variation in the equatorial electrojet, $J$. Atmos. Terr. Phys., 24, 1031-1040, 1962b.

Rastogi, R. G., Lunar tidal oscillations in the solar daily range of $H$ at equatorial stations during IGY-IGC, J. Geophys. Res., 69, 10201024, 1964.

Rastogi, R. G., Geomagnetic field variations at low latitudes and ionospheric electric field, J. Atmos. Terr. Phys., 55, 1375-1381, 1993.

Rastogi, R. G. and K. N. Iyer, Quiet day variation of geomagnetic $H$ field at low latitudes, J. Geomag. Geoelectr., 28, 461-478, 1976.

Rastogi, R. G., H. Chandra, and S. C. Chakravarty, The disappearance of equatorial $E_{\mathrm{s}}$ and the reversal of electrojet current, Proc. Ind. Acad. Sci., 74, 62-67, 1971.

Rastogi, R. G., S. Alex, and A. Patil, Seasonal variation of geomagnetic $D, H$ and $Z$ fields at low latitudes, J. Geomag. Geoelectr., 46, 115126, 1994

Rastogi, R. G., M. E. James, and D. Tripathi, Longitudinal inequalities in equatorial ionospheric electric field, Ind. J. Radio \& Space Phys., 25, 27-35, 1996a

Rastogi, R. G., H. Chandra, and M. E. James, Nocturnal variations of geomagnetic horizontal field at equatorial stations, Geophys. Res. Lett., 23, 2601-2604, 1996b.

Richmond, A. D., Modeling the ionosphere wind dynamo: A review, PAGEOPH, 131, 413-435, 1989.

Sampath, S. and T. S. G. Sastry, Results from in-situ measurements of ionospheric currents in the equatorial region-I, J. Geomag. Geoelectr., 31, 373-379, 1979a.

Sampath, S. and T. S. G. Sastry, Depth of non conducting layer in the Indian ocean region around Thumba, derived from in situ investigations of equatorial electrojet-II, J. Geomag. Geoelectr., 31, 381-389, 1979b.

Sastry, T. S. G., Quiet day electrojet over Thumba, India, J. Geophys. Res., 73, 1789-1794, 1968.

Schlapp, D. M., World-wide morphology of day-to-day variability of S, J. Atmos. Terr. Phys., 30, 1761-1776, 1968.

Schuman, B. M., Rocket measurement of the equatorial electrojet, $J$. Geophys. Res., 75, 3889-3901, 1970.

Sinha, H. S. S., H. Chandra, and R. G. Rastogi, Longitudinal inequalities in the equatorial electrojet, Proc. Nat. Acad. Sci., India, 69(A), I, 8996,1999

Somayajulu, V. V., Behaviour of harmonic components of the geomagnetic field during counter electrojet events, J. Geomag. Geoelectr., 40, 111-130, 1988.

Subbaraya, B. H., S. Prakash, and S. P. Gupta, Electron densities in the equatorial lower ionosphere from the Langmuir probe experiments conducted at Thumba during the years 1966-1978, Scientific Report ISRO-PRL-SR-15-83, 1983.

Takeda, M., Y. Yamada, and T. Araki, Simulation of ionospheric currents and geomagnetic field variations of $S$ for different solar activity, J. Atmos. Terr. Phys., 48, 277-287, 1986.

Vikramkumar, B. T., K. S. Viswanathan, and P. B. Rao, VHF backscatter radar observations of the equatorial electrojet irregularities, Ann. Geophys., 2, 495-500, 1984.

H. Chandra (e-mail: hchandra@prl.ernet.in), H. S. S. Sinha, and R. G. Rastogi 